\title{
Ranpirnase and its potential for the treatment of unresectable malignant mesothelioma
}

\author{
Camillo Porta' \\ Chiara Paglino' \\ Luciano Mutti $^{2}$ \\ 'Medical Oncology and Laboratory \\ of Pre-Clinical Oncology and \\ Developmental Therapeutics, \\ I.R.C.C.S. San Matteo University \\ Hospital Foundation, Pavia, Italy; \\ ${ }^{2}$ Local Health Authority 6, Piedmont, \\ Italy
}

\begin{abstract}
Ribonucleases are a superfamily of enzymes which operate at the crossroads of transcription and translation, catalyzing the degradation of RNA; they can be cytotoxic because the cleavage of RNA renders indecipherable its information. Ranpirnase is a novel ribonuclease which preferentially degrades tRNA, thus leading to inhibition of protein synthesis and, ultimately, to cytostasis and cytotoxicity. Ranpirnase has demonstrated antitumor activity both in vitro and in vivo in several tumor models. The maximum tolerated dose emerging from phase I studies was $960 \mathrm{~g} / \mathrm{m}^{2}$, with renal toxicity as the main dose-limiting toxicity. A large phase II trial showed that ranpirnase has disease-modifying activity against malignant mesothelioma. Ranpirnase proved to be superior to doxorubicin in a phase III trial, while preliminary results of another large, phase III trial, suggest that the combination of ranpirnase and doxorubicin could be more effective than doxorubicin alone. In all the above studies, ranpirnase seems to act mainly as a cytostatic rather than a cytotoxic drug, stabilizing progressive disease and potentially prolonging patients' survival. Ranpirnase may thus find its niche in combination with doxorubicin for mesothelioma as a second-line therapy, where no standard of care presently exists.
\end{abstract}

Keywords: ranpirnase, mesothelioma, ribonucleases, doxorubicin, antitumor activity

\section{Malignant mesothelioma: still an orphan disease}

The incidence of malignant mesothelioma (MMe), a relatively rare cancer linked to asbestos exposure, is expected to increase dramatically over the next couple of decades, both in Europe and in many developing countries (Peto et al 1999; Carbone et al 2007).

The vast majority of MMe patients present with stage III or IV, ie, mainly unresectable, disease; despite some recent advance in the medical treatment of MMe, presently the aim of the treatment for these patients is only palliation (Vogelzang et al 2005; Fennell et al 2008). A few randomized controlled trials have firmly established the use of antifolate-platinum doublets as the present treatment of choice for locally advanced unresectable or metastatic MMe patients, supporting the evidence from meta-analyses for the superior activity of platinum-based combinations (Fennell et al 2008).

Even though, theoretically, second-line therapy of MMe might have an important role in increasing survival rates, no standards have emerged so far in this setting.

Taken together, the unsatisfactory results obtained with first-line treatment options, and the lack of a standard of treatment for those patients who, still being in good condition, progress after a first-line treatment, emphasize the need for newer, active, agents for such a disease.

\section{An historic introduction to ribonucleases}

Ribonucleases, which were extensively studied in the 1960s and 1970s, are a family of enzymes well known for their physiological ability to cleave RNA; indeed, bovine 
pancreatic ribonuclease, or RNase $\mathrm{A}$, has been used as a privileged model in protein folding studies. After this early enthusiasm, ribonucleases were almost dismissed as uninteresting digestive enzymes. Only recently have they attracted attention again, owing to their remarkable and complex biological activities (Leland and Raines 2001; Benito et al 2005; Arnold and Ulbrich-Hofmann 2006; Lee and Raines 2008).

As a whole, ribonucleases are a superfamily of secretory enzymes that operate at the crossroads of transcription and translation, catalyzing the degradation of RNA; however, several other intriguing activities have been described recently. For example, angiogenin is able to promote angiogenesis (Riordan 1997), and bovine seminal ribonuclease, a unique dimeric homolog of RNase A, has relevant immunosuppressive and antitumor activities, as well as being embriotoxic and aspermatogenic (D’Alessio et al 1997).

\section{Ribonucleases: a novel class of anticancer targeted agents}

Ribonucleases can be cytotoxic due to the fact that the cleavage of RNA renders indecipherable the information it encodes.

For years, replicative DNA was the main target of anticancer agents; more recently, specific proteins endowed with receptor and/or signal transduction properties have become the main target of anticancer agents; RNA, which is in between DNA and proteins (Figure 1), only rarely has been the target of anticancer drugs (Bruserud 2007), and even then with only modest relevance, as in the case of 5-FU antitumor activity.

The cytotoxicity of pancreatic-type ribonucleases was first discovered and described in the early 1950s, when RNase A was shown to be toxic to tumor cells in vitro (Ledoux and Balthus 1954) as well as in in vivo models (Ledoux 1955).

\section{Ranpirnase}

\section{Pharmacology and mechanism of action}

Ranpirnase (P-30 protein [Onconase ${ }^{\circledR}$ ], Alfacell Corp, Bloomfield, NJ, USA) is a novel ribonuclease which, as a homolog of RNase A, belongs to the family of pancreatic ribonucleases (Ardelt et al 1991); however, it is present in the oocytes and early embryos of Rana pipiens, the Northern Leopard frog (Irie et al 1998). It is a single-chain protein, 104 amino acid residues long, with a molecular weight of about 12,000 Da (Ardelt et al 1991), an amino acid sequence $\sim 30 \%$ identical to that of RNase A (Ardelt et al 1991), and molecular structure similar to that of RNase A (Mosimann et al 1992). Owing to the presence of 4 disulfide bonds, 3 of which are conserved in RNase A, it is highly stable to heat,

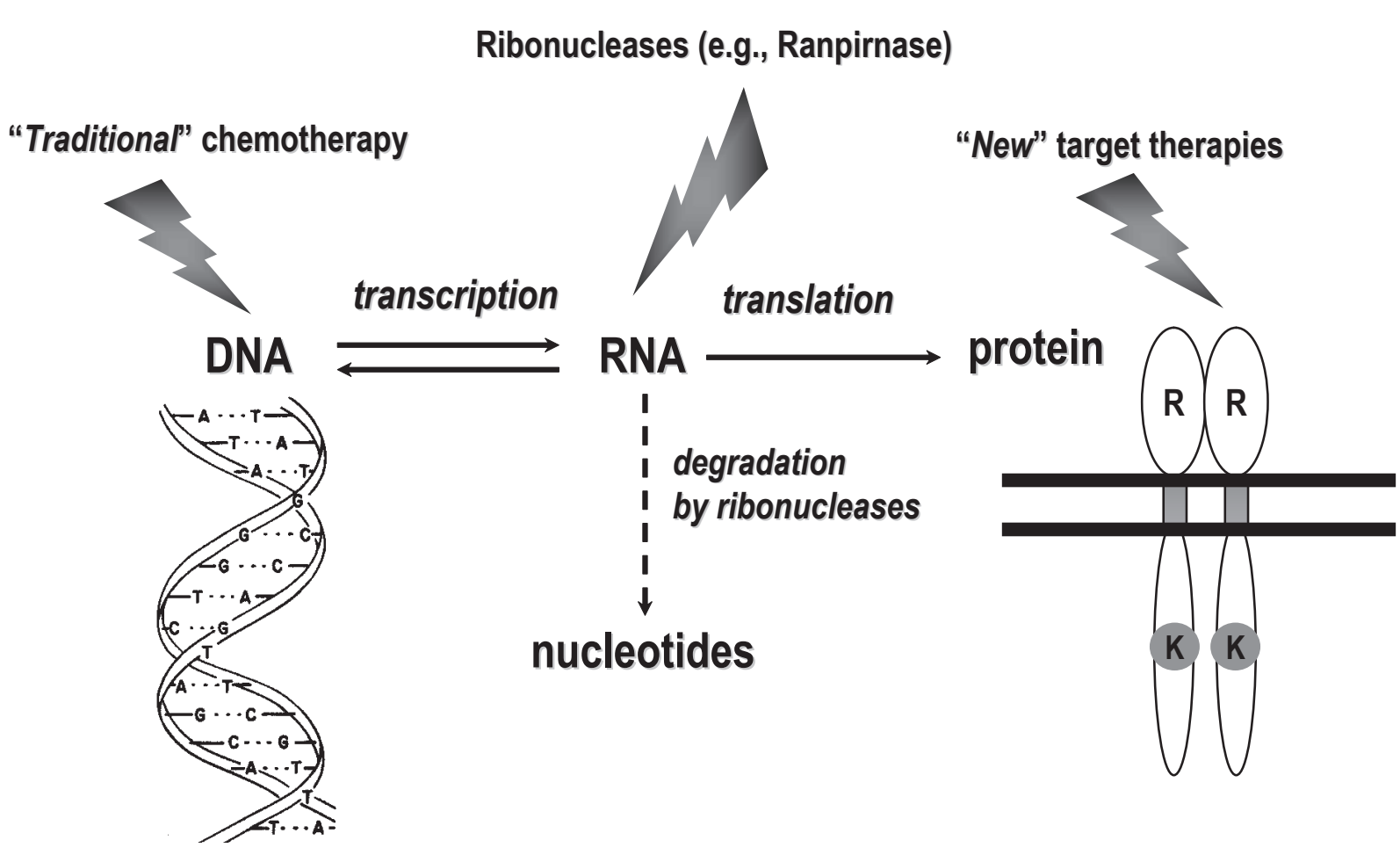

Figure I Anticancer agents usually target either DNA or proteins endowed with receptor and/or signal transduction properties. However, RNA, which is in between DNA and proteins, could also be targeted effectively by specific anticancer drugs such as ranpirnase. 
with a midpoint temperature of thermal denaturation $\left(\mathrm{T}_{\mathrm{m}}\right)$ of $90{ }^{\circ} \mathrm{C}$, almost $30^{\circ} \mathrm{C}$ higher than that of RNase A (Leland et al 1998).

Ranpirnase binds to the cell surface and uses the energy-dependent endocytic process to penetrate into the cell (Wu et al 1993), routed through the Golgi apparatus to the cytosol, where it preferentially degrades tRNA (but not ribosmal and mRNA) by catalyzing the cleavage of the P-O5' bond of RNA on the 3' side of pyrimidine nucleosides (Iordanov et al 2000a).

This RNA degradation leads to inhibition of protein synthesis and, ultimately, to the cytostatic and cytotoxic activity of ranpirnase. Indeed, ranpirnase plays a cytostatic role, arresting the cell cycle in $\mathrm{G}_{1}$ (Darzynkiewicz et al 1988; Juan et al 1998), as well as a cytotoxic role, acting as a cytotoxin (Wu et al 1993). Evidence suggests that the irreparable tRNA damage induced by ranpirnase may constitute a pro-apoptotic signal (Iordanov et al 2000a); the apoptosis triggered by ranpirnase seems to be mainly caspase-dependent, even though a caspase-independent mechanism has been recently described (Michaelis et al 2007). Furthermore, p53 status does not affect ranpirnase-induced apoptosis (Costanzi et al 2005), a key feature of ranpirnase, since it is well known that many tumors carry an inactivated p53, which, in turn, can suppress or reduce the apopototic process activated by several chemotherapeutic agents.

The superior activity of ranpirnase on tumor cells, compared with normal cells, has been explained molecularly by an elegant in vitro study by Iordanov et al (2000b), in which the authors investigated whether ranpirnase activates two signal-transduction pathways commonly stimulated by conventional chemo- and radio-therapy, ie, the stressactivated protein kinase (SAPK) and the nuclear factor-kB (NFkB) pathways. Ranpirnase proved to be a potent activator of SAPK1 (JNK-1 and -2) and SAPK2 (p38 MAP kinase), but not NFkB; using explanted fibroblasts from mice containing targeted disruption of both jnk-1 and -2 alleles, the authors found that JNKs are important mediators of ranpirnase-induced cytotoxicity. Surprisingly, after immortalization of these same cells with human papilloma virus 16 (HPV 16) gene products E6 and E7, additional proapoptotic pathways were activated, thus suggesting that, in cancer cells, ranpirnase is more proapoptotic, inducing several different pathways.

Notably, ranprinase proved not to be a substrate for the MDR1 gene product p-glycoprotein (pGP), one of the major factors responsible for resistance to cytotoxic chemotherapy; indeed, at least one in vitro study demonstrated that the cytotoxic effect of ranpirnase was unrelated to $\mathrm{P}$-gp expression levels, with an $\mathrm{IC}_{50}$ of approximately $6 \times 10^{-5} \mathrm{M}$ in both wild-type as well as MDR1-transfects cancer cells (Rybak et al 1996).

Ribonuclease activity is regulated by the presence of cytosolic, class-specific, inhibitors of its enzymatic activity, globally known as ribonuclease inhibitor (RI). Even though the precise biological role of these inhibitors is still far from perfectly known, they act to protect cellular RNA if a ribonuclease inadvertently enters the cytosol (Hofsteenge 1997); remarkably, RI is not so powerful in inhibiting ranpirnase catalysis (Leland and Raines 2001). Indeed, the $\mathrm{K}_{\mathrm{i}}$ value for the inhibition of ranpirnase by RI is estimated to be $\geq 10^{-6} \mathrm{M}$, which is more than $10^{7}$-fold greater than the $\mathrm{K}_{\mathrm{d}}$ value for the RI-RNase A complex (Boix et al 1996).

Further insights into the antitumor activity of ranprinase have been reported recently. Ardelt et al (2007) suggested that ranprinase is able to decrease the generation of reactive oxygen species, as well as the mitochondrial transmembrane potential in vitro, and that such a suppression of intracellular oxidative stress may contribute to the cytotoxic and pro-apoptotic activity of the drug, when combined with cytotoxic agents); indeed, even though oxidative stress is generally regarded as pro-apoptotic, it may also interfere with cancer chemotherapy, as demonstrated in a Burkitt's lymphoma model, where apoptosis induced by several chemotherapeutic agents, including doxorubicin, was inhibited by hydrogen peroxide (Shacter et al 2000). Therefore, the antioxidative function of ranpirnase has been regarded as an important element of its antiproliferative/cytotoxic activity towards cancer cells, and a possible mechanism of its well-documented synergism with other anticancer agents (Mikulski et al 1990, 1992; Rybak et al 1996; Deptala et al 1998).

Other studies suggest that ranpirnase could also act as a radiation sensitizer (Lee et al 2007a), and that such a novel activity is due, on the one hand, to the inhibition of oxygen consumption $\left(\mathrm{QO}_{2}\right)$ and, on the other, to the inhibition of sublethal damage repair, both in vitro and in vivo in a xenograft model of lung cancer (Lee et al 2000a; Kim et al 2007).

Finally, another recent study demonstrated that multiple, small doses of ranpirnase increased apoptosis and cytotoxicty of A549 non-small-cell lung cancer, both in vitro (Lee et al 2007b) and in vivo (Lee and Shogen 2008), thus suggesting the use of alternative schedules of the drug.

\section{Preclinical activity}

In vitro, ranpirnase has demonstrated both cytostatic and cytotoxic effects on several murine and human cell lines 
(Costanzi et al 2005; Pavlakis and Vogelzang 2006), as a single-agent, as well as in combination with other agents. The prevalent type of response to ranpirnase observed in established human cancer cell lines is summarized in Table 1.

Against MMe cell lines, ranpirnase has been shown to inhibit cell growth, both in vitro and in vivo (Costanzi et al 2005); indeed, it proved able to prolong survival of tumor-bearing mice, compared with controls, an activity that has been documented in many different xenograft models (Costanzi et al 2005). Table 2 summarizes ranprinase activity in different animal models.

Enhanced cytotoxicity has been seen with coadministration of ranpirnase with several anticancer drugs, including tamoxifen (Mikulski et al 1990, 1992), cisplatin (Mikulski et al 1992; Lee et al 2007b), doxorubicin (Mikulski et al 1999), vincristine (Rybak et al 1996), and also with phosphatidyl inositol-3 kinase inhibitors (Ramos-Nino et al 2005).

\section{Biodistribution and toxic effects in animals}

Biodistribution studies in mice have shown that iv ranpirnase is taken up primarily by the kidneys $(60 \%-70 \%$ of injected dose at 15 minutes), while liver uptake is minimal, although prolonged retention by the liver has been observed (Vasandani et al 1996). In the kidney, after 1 week of treatment, and more evidently after 3 weeks, there was evidence of acute moderate multifocal proximal renal tubular necrosis, a toxicity that was reversed 2 weeks after drug withdrawal; in the liver, toxic effects (once again reversibile) were seen in the hepatocytes, with lipidosis, cellular swelling, vacuolar degeneration and apoptosis in mice treated for 1 or 3 weeks (Vasandani et al 1999).

\section{Phase I studies}

Two phase I studies evaluating the optimum dose and schedule of ranpirnase have been performed. In the first of these studies, ranpirnase was studied using a daily schedule of iv administration beginning at $6 \mathrm{~g} / \mathrm{m}^{2} /$ day and closing at $105 \mathrm{~g} / \mathrm{m}^{2} /$ day, without determining a maximum tolerated dose (MTD). One patient developed renal failure requiring dialysis at the dose level of $80 \mathrm{~g} / \mathrm{m}^{2}$. Three $(9.3 \%)$ of the 32 patients enrolled showed disease stabilization as their best response to treatment (Costanzi et al 2005).

In the second phase I study, ranpirnase was administered iv as a single agent on a weekly schedule at 5 dose levels, in the range of $60-1200 \mathrm{~g} / \mathrm{m}^{2}$. A total of 71 patients were thus treated, and the MTD was established as $960 \mathrm{~g} / \mathrm{m}^{2}$. In this study, some objective responses were observed in lung cancer (1 partial response), esophageal carcinoma (1 partial response), and colorectal carcinoma ( 1 minor response) patients, while stable diseases were observed in other patients with different tumors. Thus, the recommended phase II dose using this weekly schedule was $480 \mathrm{~g} / \mathrm{m}^{2} /$ week (Mikulski et al 1993).

In the phase I study of the weekly schedule, the doselimiting toxicity was renal, manifested by proteinuria with or without azotemia, peripheral edema, and fatigue. Other toxicities included flushing, myalgias, transient dizziness, and decreased appetite. Transient hypotensive reactions preceded by flushing that responded quickly to volume expansion were also observed. Notably, no significant myelosuppression, mucositis, alopecia, cardiotoxicity, coagulopathy, or hepatotoxicity was observed.

Table I Prevalent type of response to ranpirnase observed in established human cancer cell lines in vitro

\begin{tabular}{lll}
\hline Human cell line & Author & $\begin{array}{c}\text { Prevalent type of response } \\
\text { to ranpirnase observed }\end{array}$ \\
\hline A549 (NSCLC) & Lee et al 2000 & cytotoxic \\
ASPC-I (pancreas) & & \\
HepG2 (hepatoma) & & pro-apoptotic \\
LSI74T (colon) & Halicka et al 1996 & cell cycle delay (all phases) or arrest \\
U937 (lymphoma) & & \\
HL 60 (leukemia) & Darzynkiewicz & \\
Colo 320 CM (colon) & et al I988 & \\
A-253 (submaxillary & & cell cycle arrest in G, \\
carcinoma) & & Juan et al 1998 \\
HL 60 (leukemia) & & \\
U937 (histocytic lymphoma) &
\end{tabular}


Table 2 In vivo activity of ranpirnase in animal models

\begin{tabular}{|c|c|c|}
\hline Model & Author & Prevalent activity \\
\hline HT29MDRI colon cancer xenograft & Rybak et al 1996 & $\begin{array}{l}\text { In association with vincristine, ranpirnase } \\
\text { overcame MDRI-mediated resistance }\end{array}$ \\
\hline $\begin{array}{l}\text { MI09 Madison mouse carcinoma } \\
\text { in mice }\end{array}$ & Mikulski et al 1990 & $\begin{array}{l}\text { Ranpirnase slowed tumor growth, increas- } \\
\text { ing survival (in the Madison mouse model) }\end{array}$ \\
\hline $\begin{array}{l}\text { MDA-MB-23 I human breast } \\
\text { cancer in nude mice }\end{array}$ & Mikulski et all999 & $\begin{array}{l}\text { Ranpirnase synergized with doxorubicin, } \\
\text { increasing survival }\end{array}$ \\
\hline $\begin{array}{l}\text { Daudi cells given intraperitoneally } \\
\text { in SCID mice }\end{array}$ & Newton et al 200I & $\begin{array}{l}\text { Ranpirnase synergized with the anti- } \\
\text { CD22 monoclonal antibody epratuzumab, } \\
\text { increasing survival }\end{array}$ \\
\hline $\begin{array}{l}\text { H4I IE rat hepatoma } \\
\text { MCalV murine adenocarcinoma } \\
\text { FSall murine fibrosarcoma } \\
\text { DUI } 45 \text { human prostate cancer in } \\
\text { nude mice }\end{array}$ & Lee et al $2000 b$ & Ranpirnase inhibited tumor growth \\
\hline $\begin{array}{l}\text { AsPC-I human pancreatic carci- } \\
\text { noma in nude mice }\end{array}$ & Lee et al 2003 & \\
\hline
\end{tabular}

\section{Phase II studies in tumors other than mesothelioma}

Ranpirnase has been studied in phase II trials as a single agent in patients with non-small-cell lung cancer (Costanzi et al 1995; Mikulski et al 1995), breast cancer (Puccio et al 1996), and renal cell cancer (Vogelzang et al 1999), and in combination with tamoxifen in pancreatic (Chun et al 1995) and prostate cancer (Costanzi et al 2005).

In the preliminary report of the phase II study in non-small-cell lung cancer, ranpirnase (given at $240 \mathrm{~g} / \mathrm{m}^{2}$ ) as a single agent induced no objective responses in the 30 patients evaluated; however, 5 patients (17\%) achieved disease stabilization, with a resulting median survival time of 7.7 months (Costanzi et al 1995; Mikulski et al 1995).

A small study, reported in abstract form (Puccio et al 1996), demonstrated a limited clinical benefit in breast cancer (1 minor response and 2 disease stabilizations out of 17 patients).

In 14 patients with refractory advanced renal cell cancer, ranpirnase, given at a dose of $480 \mathrm{~g} / \mathrm{m}^{2} /$ week, proved to be inactive in terms of antitumor activity, but yielded encouraging results in terms of median survival time (Vogelzang et al 1999).

In a phase I/II pancreatic cancer study, ranpirnase recommended dose was $480 \mathrm{mg} / \mathrm{m}^{2}$, while tamoxifen was started 7 days prior the first ranpirnase dose to allow for the accumulation of the drug within the tumor, as suggested by a pre-clinical model; such a combination yielded 1 complete, 2 minor responses, and 7 disease stabilizations out of 32 evaluable patients, suggesting a potential activity of the combination in pancreatic cancer (Chun et al 1995; Costanzi et al 2005).
Another study addressed the antitumor activity of ranpirnase when given in combination with tamoxifen in patients with early prostate cancer recurrence, as evidenced by rising prostate specific antigen (PSA) test after prostatectomy or radiation therapy. The study has not been reported in extenso so far, having been addressed only within the review by Costanzi et al (2005). Among the 13 patiente enrolled in this small study, 6 discontinued treatment owing to toxicity before completing 3 cycles of treatment, and only 1 patient showed stable PSA levels, suggesting an extremely low activity of the of the ranpirnase/tamoxifen combination in this setting.

\section{Phase II study in malignant mesothelioma} A single-arm, open-label, multicenter phase II trial of ranpirnase as a single agent has been performed in MMe patients, the largest phase II study of this drug undertaken (Mikulski et al 2002).

The aim was to evaluate the drug's clinical efficacy and safety in this orphan disease; survival was the primary end point, while secondary end points were tumor response and time to progression. All patients received weekly iv infusions of ranpirnase at an initial dose of $480 \mathrm{~g} / \mathrm{m}^{2}$.

Patients $(\mathrm{n}=105)$ with an ECOG performance status score of 0-2, were enrolled; the Cancer and Leukemia Group B (CALGB) prognostic group criteria (Herndon et al 1998) were used to define treatment target groups (TTGs). This study prospectively used an intent-to-treat (ITT) analysis that included all patients enrolled, and retrospectively used the TTG analysis that included only those patients who met the predefined criteria for the CALGB prognostic groups 
1-4 combined $(n=81)$. Using the Kaplan-Meier method, the overall median survival time was 6 months (95\% confidence interval [CI]: 4.7-10.0 months) and 8.3 months for the ITT populations; the 1- and 2-year survival rates were $34.3 \%$ and $21.6 \%$, respectively, for the ITT population, and $42 \%$ and $26.8 \%$ for TTG, respectively. The median survival times for the CALGB groups 1-6 were 29.9, 6.6, 5.8, 10.7, 4.5, and 1.8 months, respectively. As expected, survival was longest for the best prognostic group and shortest for the worst group. Survival analysis of patients who had prior chemotherapy vs those who had not was not significantly different (median survival time: 7.3 vs 5.7 months; 1-year survival rate: 33.3 versus $34.9 \%$; 2-year survival rate: 19.7 vs $22.7 \%$; $\log$-rank $\mathrm{p}=0.971)$. Patients with better performance status and epithelioid histology had, as expected, more favorable survival. Among the 81 patients assessable for investigator-assessed tumor response, 4 had partial responses (PR), 2 had minor responses (MR), and 35 experienced disease stabilization (SD) (Mikulski et al 2002).

Twenty-two patients developed grade $3(n=18)$ or $4(n=4)$ adverse events that were considered related to treatment. As expected on the basis of the phase I experience, treatment was associated with asthenia, flu-like symptoms, arthralgia, fever, vasodilation (manifesting as flushing with occasional hypotension and/or vasovagal reaction), paraesthesias, peripheral edema, renal insufficiency, and allergic reactions.

This study clearly suggested that ranpirnase mainly acts as a cytostatic agent, as do many other molecularly targeted drugs. Indeed, conventional radiological measurements and commonly used response criteria (eg, the RECIST ones) are not be the best way to evaluate the antitumor activity of drugs such as ranpirnase, time-dependent end points being more useful (Korn et al 2001; Pavlakis and Vogelzang 2006).

As a whole, this phase II trial in MMe clearly suggested that ranpirnase may have disease-modifying activity in $\mathrm{MMe}$, justifying the subsequent move to phase III.

\section{Phase III studies in malignant mesothelioma}

Based on positive combination preclinical studies, ranpirnase could be combined with either cisplatin or doxorubicin, both established active agents for MMe (Vogelzang et al 2005; Fennel et al 2008). However, in view of its potential for renal toxicity, doxorubicin seemed the obvious choice for combination in order to avoid potential overlapping renal toxicity with cisplatin.

Thus, in an initial phase III study in MMe, patients were randomized to receive ranpirnase $\left(480 \mathrm{~g} / \mathrm{m}^{2}\right.$ iv weekly) or doxorubicin (60 $\mathrm{mg} / \mathrm{m}^{2}$ iv q21 days) using a $3: 2$ randomization ratio (Vogelzang et al 2000). This was an open-label, multi-center, randomized controlled trial which enrolled 154 patients with MMe who were either chemotherapy-naïve or had failed one prior chemotherapy regimen; patients were stratified by performance status ( 0 vs 1$)$ and histology (epithelioid vs non-epithelioid). The primary end point of the study was overall survival by ITT.

Final results (available on 144 patients, 75 treated with ranpirnase and 69 with doxorubicin), showed no significant differences between the two arms (Table 3a).

Analysis by CALGB prognostic groups, however, revealed an excess of poor prognosis patients (groups 5 and 6) in the ranpirnase arm (37\%) compared with the doxorubicin $\operatorname{arm} \operatorname{arm}(17 \%)$.

A post-hoc analysis was thus performed excluding these patients and those with unconfirmed MMe by centralized pathological review (additional $\mathrm{n}=5$ ). TTGs were defined based on the CALGB prognostic groups, as evaluated in the above-mentioned phase II study. The results of this analysis clearly favored ranpirnase, as shown in Table 3b; indeed, a Cox proportional hazards regression analysis revealed a survival risk ratio of 1.34 in favor of ranpirnase treatment in the ITT population, allowing for histology, age, sex, CALGB prognostic groups and abdominal involvement (95\% CI: $0.93-1.94 ; p=0.12$ ). In the post-hoc TTG analysis, the same Cox proportional hazards regression analysis revealed a survival risk ratio of 1.60 in favor of ranpirnase treatment (95\% CI: 1.03-2.50; $\mathrm{p}=0.04)$.

Few grade $3 / 4$ toxicities were observed (Table 4 ), the most commonly reported being asthenia $(10.8 \%)$, and ranpirnase toxicities were mainly reversible on drug discontinuation (Vogelzang 2000). Furthermore, owing to protocol-mandated dose reduction for renal toxicity, no serious renal toxicity

Table 3 Results of the first phase III trial of ranpirnase vs doxorubicin in MMe patients according to the patient population considered:ITT (a) or TTG (b) (Vogelzang 2000)

\begin{tabular}{lll}
\hline a & $\begin{array}{l}\text { Ranpirnase-treated } \\
\text { patients }\end{array}$ & $\begin{array}{l}\text { Doxorubicin-treated } \\
\text { patients }\end{array}$ \\
\hline Median survival & 8.4 months & 8.2 months \\
I-year survival rate & $33.3 \%$ & $34.8 \%$ \\
2-year survival rate & $13.7 \%$ & $10.9 \%$ \\
b & Ranpirnase-treated & Doxorubicin-treated \\
& patients & patients \\
Median survival & II.6 months & 9.6 months \\
I-year survival rate & $46.8 \%$ & $38.6 \%$ \\
2-year survival rate & $20.9 \%$ & $13.2 \%$ \\
\hline
\end{tabular}


Table 4 Grade III and IV toxicities observed in the phase III study of ranpirnase vs doxorubicin in MMe (according to the National Cancer Institute of Canada [NCIC] classification) (Vogelzang 2000)

\begin{tabular}{|c|c|c|c|c|}
\hline \multirow[b]{3}{*}{ Toxicity } & \multicolumn{4}{|c|}{ Ranpirnase } \\
\hline & \multicolumn{2}{|l|}{ G3 } & \multicolumn{2}{|l|}{ G4 } \\
\hline & no. & $\%$ & no. & $\%$ \\
\hline Asthenia & 9 & 10.8 & 1 & 1.2 \\
\hline Arthralgia/myalgia & 4 & 4.8 & 0 & 0 \\
\hline Paresthesias & 4 & 4.8 & 0 & 0 \\
\hline Dyspnea & 4 & 4.8 & 0 & 0 \\
\hline Edema & 2 & 2.4 & 0 & 0 \\
\hline $\begin{array}{l}\text { Anaphylactoid } \\
\text { reaction }\end{array}$ & 0 & 0 & 1 & 1.2 \\
\hline \multirow{3}{*}{$\begin{array}{l}\text { Nausea and } \\
\text { vomiting }\end{array}$} & 0 & 0 & I & 1.2 \\
\hline & \multicolumn{4}{|c|}{ Doxorubicin } \\
\hline & $\overline{\mathbf{G 3}}$ & & G4 & \\
\hline Toxicity & no. & $\%$ & no. & $\%$ \\
\hline Asthenia & 2 & 4.5 & 0 & 0 \\
\hline Fever & 2 & 4.5 & 1 & 2.3 \\
\hline Anorexia & I & 2.3 & 0 & 0 \\
\hline Mucositis & 1 & 2.3 & 0 & 0 \\
\hline $\begin{array}{l}\text { Nausea and } \\
\text { vomiting }\end{array}$ & I & 2.3 & 1 & 2.3 \\
\hline
\end{tabular}

was observed, thus supporting the view that ranpirnase, when administered with appropriate attention for hypersensitivity and with monitoring and dose adjustment for renal impairment, is a relatively safe and well-tolerated treatment (Pavlakis and Vogelzang 2006).

After the aforementioned phase III trial, another multicenter, randomized, controlled, phase III study, to be performed on a global scale, was designed: the $\mathrm{P} 30-302$ protocol, entitled "Onconase ${ }^{\circledR}$ plus Doxorubicin versus Doxorubicin alone for patients with malignant pleural or peritoneal mesothelioma who have had no more than one prior chemotherapy regimen".

In this study, patients with proven mesothelioma were randomized to receive either doxorubicin $60 \mathrm{mg} / \mathrm{m}^{2}$ iv every 3 weeks or iv ranpirnase weekly (given at $240 \mathrm{~g} / \mathrm{m}^{2}$ in cycle 1 , to be escalated to $480 \mathrm{~g} / \mathrm{m}^{2}$ from cycle 2 in the absence of serious toxicity), followed by doxorubicin $60 \mathrm{mg} / \mathrm{m}^{2}$ iv every 3 weeks. Patients were stratified according to the CALGB prognostic groups (1-4) and histology, and were randomized in a 1:1 fashion. The primary end point of the study was overall survival. This study has been recently closed to enrollment, but its final results are not yet available.

An interim analysis was performed per protocol at the occurrence of 105 deaths. The key findings were as follows (pers comm., Shogen K).
Overall median survival time (MST), the primary endpoint of the study, favored the ranpirnase plus doxorubicin treatment group (12 months) over the doxorubicin group (10 months). A 2-month improvement in median survival has also been observed previously in the TTG analysis ( $\mathrm{N}=104)$ from the completed phase III single agent study that favored the ranpirnase group over the doxorubicin group (11.6 months vs 9.6 months).

Other results of this interim analysis included: at 1 year, $47 \%$ of the ranpirnase plus doxorubicin-treated subjects were alive compared with $36 \%$ of patients treated with doxorubicin only. Subjects evaluable for clinical response (those with evidence of tumor regression or stabilization of disease for a minimum of 3 months) showed a 7-month difference in MST (17 vs 10 months) favoring the ranpirnase plus doxorubicin group vs the doxorubicin group.

The analysis of safety data revealed that ranpirnase, when given with doxorubicin, did not increase the number or severity of known doxorubicin-associated side effects. The most frequent side effects reported for both treatment groups included nausea, fatigue, and alopecia. The incidence of these events was comparable for both treatment groups.

\section{Conclusions}

Ranpirnase is a ribonuclease endowed with potent antitumor properties; its mechanism of action is completely novel since, by degrading tRNA, it acts both as a cytotoxic and a cytostatic drug; furthermore, owing to both its in vitro synergy with other cytotoxic agents, and its tolerability as a single agent, it is amenable to combination with traditional chemotherapeutic drugs, eg, doxorubicin and cisplatin.

Since its early clinical development, it has held great promise for the treatment of $\mathrm{MMe}$, where it seems to act mainly as a cytostatic agent, thus stabilizing the disease. Indeed, ranpirnase proved to be superior to doxorubicin within a phase III trial, while preliminary results of another large, phase III trial suggest that the combination of ranpirnase and doxorubicin could be more effective than doxorubicin alone

Ranpirnase appears to be generally well tolerated with predicable and reversible toxicity, and with very few serious adverse events; furthermore, dose modifications are usually required only for changes in renal function.

Unfortunately for the development of the drug, during the course of its phase III development, the combination of pemetrexed and a platinum derivative emerged as the standard first-line treatment for MMe patients in. This led to a slowing of the recruitment into the $\mathrm{P} 30-302$ protocol 
and clearly reduced the interest for its use as a first-line treatment.

Thus, while waiting the final results of the above study, it appears clear that ranpirnase may find its niche (in combination with doxorubicin) for second-line therapy of $\mathrm{MMe}$ (Pavlakis and Vogelzang 2006) where, at present, no standard of care exists.

However, the current understanding of its mechanism of action, coupled with its favorable toxicity profile, characterized by a lack of major toxicities, especially in terms of hematology, make ranpirnase an appealing drug to use in combination with other anticancer agents, as well as with radiotherapy. This could clearly open a new frontier for the use of this novel drug in tumor types other than MMe.

\section{Acknowledgments}

We gratefully thank Dr. Kuslima Shogen from Alfacell for providing, for the purpose of this review, the above summarized preliminary data relative to the still unpublished phase III study of doxorubicin plus or minus ranpirnase in MMe.

This work has been supported by the Italian Group for Mesothelioma (G.I.Me.) and by Fondazione Buzzi-Unicem

\section{Disclosures}

None of the authors has any conflicts of interest to disclose.

\section{References}

Ardelt W, Mikulski SM, Shogen K. 1991 Amino acid sequence of an anti-tumor protein from Rana pipiens oocytes and early embryos. Homology to pancreatic ribonucleases. J Biol Chem, 266:245-51.

Ardelt B, Juan G, Burfeind P, et al. 2007. Onconase, an anti-tumor ribonuclease, suppresses intracellular oxidative stress. Int $J$ Oncol, 31:663-9.

Arnold U, Ulbrich-Hofmann R. 2006. Natural and engineered ribonucleases as potential cancer therapeutics. Biotechnol Lett, 28:1615-22.

Benito A, Ribó M, Vilanova M. 2005. On the track of antitumour ribonucleases. Mol Biosyst, 1:294-302.

Boix E, Wu Y, Vasandani VM, et al. 1996. Role of the N terminus in RNase A homologues. Differences in catalytic activity, ribonuclease inhibitor interaction and cytotoxicity. J Mol Biol, 257:992-1007.

Bruserud O. 2007. Introduction: RNA and the treatment of human cancer. Curr Pharm Biotechnol, 8:318-9.

Carbone M, Emri S, Dogan AU, et al. 2007. A mesothelioma epidemic in Cappadocia: scientific developments and unexpected social outcomes. Nat Rev Cancer, 7:147-54.

Chun H, Costanzi J, Mittelman A, et al. 1995, Phase I/II trial of onconase (ONC) plus tamoxifen (TMX) in patients (pts) with advanced pancreatic carcinoma (APC) [abstract]. Proc Am Soc Clin Oncol, 517.

Costanzi J, Sidransky D, Navon A, et al. 2005. Ribonucleases as a novel pro-apoptotic anticancer strategy: review of the pre-clinical and clinical data for ranpirnase. Cancer Invest, 23:643-50.

D’Alessio G, Di Donato A, Mazzarella L, et al. 1997. Seminal ribonuclease: the importance of diversity. In: D'Alessio G, Riordan JF (eds.) Ribonucleases: structures and functions. New York, NY, U $S$ : Academic Press. pp. 383-423.
Darzynkiewicz Z, Carter SP, Mikulski SM, et al. 1988. Cytostatic and cytotoxic effect of Pannon (P-30 protein), a novel anticancer agent. Cell Tissue Kinet, 21:169-82.

Deptala A, Halicka HD, Ardelt B, et al. 1998. Potentiation of tumor necrosis factor-induced apoptosis by Onconase. Int J Oncol, 13:11-6.

Fennell DA, Gaudino G, O'Byrne KJ, et al. 2008. Advances in the systemic therapy of malignant pleural mesothelioma. Nat Clin Pract Cancer, 5:136-47.

Halicka DH, Juan G, Ardelt B, et al. 1996. Induction of differentation and apoptosis of U937 and HL-60 cells by Onconase: potentiation by inhibitors of protein kinases. Proc Am Soc Clin Oncol, 15:18 (abs.).

Herndon JE, Green MR, Chahinian AP, et al. 1998. Factors predictive of survival among 337 patients with mesothelioma treated between 1984 and 1994 by the Cancer and Leukemia Group B. Chest, 113:723-31.

Hofsteenge J. 1997. Ribonuclease inhibitor. In: D'Alessio G, Riordan JF (eds.). Ribonucleases: structures and functions. New York, NY, USA: Academic Press. pp. 621-58.

Iordanov MS, Ryabinina OP, Wong J et al. 2000. Molecular determinants of apoptosis induced by the cytotoxic ribonuclease onconase: evidence for cytotoxic mechanisms different from inhibition of protein synthesis. Cancer Res, 60:1983-94.

Iordanov MS, Wong J, Newton Dl, et al. 2000. Differential requirements for the stress-activated protein kinase/c-Jun $\mathrm{NH}(2)$ terminal kinase in RNA damage-induced apoptosis in primary and in immortalized fibroblasts. Mol Cell Biol Res Commun, 4:122-8.

Irie M, Nitta K, Nonaka T. 1998. Biochemistry of frog ribonucleases. Cell Mol Life Sci, 54:775-84.

Juan G, Ardelt B, Li X, et al. 1998. G arrest of U937 cells by onconase is associated with suppression of cyclin D3 expression, induction of $\mathrm{p} 16^{\mathrm{INK} 4 \mathrm{~A}}, \mathrm{p} 21^{\mathrm{WAF} 1 / \mathrm{CIP1} 1}$ and $\mathrm{p} 27^{\mathrm{KIP}}$ and decreased $\mathrm{pRB}$ phosphorylation. Leukemia, 12:1241-8

Kim DH, Kim EJ, Kalota A, et al. 2007. Possibile mechanisms of improved radiation response by cytotoxic RNase, Onconase, on A549 human lung cancer xenografts of nude mice. Adv Exp Med Biol, 599:53-9.

Korn EL, Arbuck SG, Pluda JM, et al. 2001. Clinical trial designs for cytostatic agents: are new approaches needed? J Clin Oncol, 19:265-72.

Ledoux L, Balthus E. 1954. Action de la ribonucléase sur les cellules du carcinoma d'Erlich. Experientia, 10:500-1.

Ledoux L. 1955. Action of ribonuclease on two solid tumours in vivo. Nature, 176:36-7.

Lee I, Lee YH, Mikulski SM, et al. 2000. Enhanced cellular radiation sensitivity of androgen-independent human prostate tumor cells by Onconase. Anticancer Res, 20:1037-40.

Lee I, Lee YM, Mikulski SM, et al. 2000. Tumoricidal effects of Onconase on various tumors. $J$ Surg Oncol, 73:164-71.

Lee I, Lee YM, Mikulski SM, et al. 2003. Effect of Onconase \pm tamoxifen on ASPC-1 human pancreatic tumors in nude mice. Adv Exp Med Biol, 530:187-96.

Lee I, Kalota A, Gerwitz AM, et al. 2007. Antitumor efficacy of the cytotoxic RNase, Ranpirnase, on A549 human lung cancer xenografts of nude mice. Anticancer Res, 27:299-308.

Lee I, Kim DH, Sunar U, et al. 2007. The therapeutic mechanism of ranpirnase-induced enhancement of radiation response on A549 human lung cancer. In Vivo, 21:721-8.

Lee I, Shogen K. 2008. Mechanism of enhanced tumoricidal efficacy of multiple small dosages of Ranpirnase, the novel cytotoxic ribonuclease, on lung cancer. Cancer Chemother Pharmacol, 62:337-46.

Lee JE, Raines RT. 2008. Ribonucleases as novel chemotherapeutics: the ranpirnase example. BioDrugs, 22:53-8.

Leland PA, Schultz LW, Kim BM, et al. 1998. Ribonuclease A variants with potent cytotoxic activity. Proc Natl Acad Sci U S A, 95:10407-12.

Leland PA, Raines RT. 2001. Cancer chemotherapy - ribonucleases to the rescue. Chem Biol, 8:405-13.

Michaelis M, Cinatl J, Anand P, et al. 2007. Onconase induces caspaseindependant cell death in chemoresistant neurobastoma cells. Cancer Lett, 250:107-16. 
Mikulski SM, Ardelt W, Shogen K, et al. 1990. Striking increase of survival of mice bearing M109 Madison carcinoma treated with a novel protein from amphibian embryos. J Natl Cancer Inst, 82:151-3.

Mikulski SM, Viera A, Ardelt W, et al. 1990. Tamoxifen and trifluoroperazine (Stelazine) potenziate cytostatic/cytotoxic effects of P-30 protein, a novel protein possessing anti-tumour activity. Cell Tissue Kinet, 23:237-46.

Mikulski SM, Viera A, Shogen K. 1992. In vitro synergism between a novel amphibian oocytic ribonuclease (Onconase) and tamoxifen, lovastatin and cisplatin, in human OVCAR-3 ovarian carcinoma cell line. Int J Oncol, 1:77-85.

Mikulski SM, Grossman AM, Carter PW, et al. 1993. Phase I human clinical trial of Onconase (P-30 protein) administered intravenously on a weekly schedule in cancer patients with solid tumors. Int J Oncol, 3:57-64.

Mikulski SM, Chun HG, Mittelman A, et al. 1995. Relationship between response rate and median survival in patients with advanced non-small cell lung cancer: comparison of - Onconase ${ }^{\circledR}$ with other anticancer agents. Int J Oncol, 6:889-97.

Mikulski SM, Newton DL, Wiltrout RH, et al. 1999. Onconase and doxorubicin synergy in prolonging survival of MDA-MB-231 human breast cancer-bearing nude mice [abstract]. Proc Am Assoc Cancer Res, 40:491(abs. 3246).

Mikulski SM, Costanzi JJ, Vogelzang NJ, et al. 2002. Phase II trial of a single weekly intravenous dose of ranpirnase in patients with unresectable malignant mesothelioma. J Clin Oncol, 20:274-81.

Mosimann SC, Johns KL, Ardelt W, et al. 1992. Comparative molecular modeling and crystallization of P-30 protein: a novel antitumor protein of Rana pipiens oocytes and early embryos. Proteins, 14:392-400.

Newton DL, Hansen HJ, Mikulski SM, et al. 2001. Potent and specific antitumor effects of an anti-CD22-targeted cytotoxic ribonuclease: potential for the treatment of non-Hodgkin lymphoma. Blood, 97:528-35.

Pavlakis N, Vogelzang NJ. 2006. Ranpirnase - an antitumour ribonuclease: its potential role in malignant mesothelioma. Expert Opin Biol Ther, 6:391-9.

Peto J, Recarli A, La Vecchia C, et al. 1999. The European mesothelioma epidemic. Br J Cancer, 79:666-72.
Puccio C, Mittelman A, Chun H et al. 1996. A new anticancer RNase (Onconase): clinical trial in patients (pts) with breast cancer (BC) [abstract]. Proc Am Soc Clin Oncol, 242.

Ramos-Nino ME, Vianale G, Sabo-Attwood T, et al. 2005. Human mesothelioma cells exhibit tumor cell-specific differences in phosphatidylinositol 3-kinase/AKT activity that predict the efficacy of Onconase. Mol Cancer Ther, 4:835-42.

Riordan JF. Structure and function of angiogenin. 1997. In: D'Alessio G, Riordan JF (eds.). Ribonucleases: structures and functions. New York, NY, US A: Academic Press. pp. 445-89.

Rybak SM, Pearson JW, Foglerwe, et al. 1996. Enhancement of vincristine cytotoxicity in drug-resistant cells by simultaneous treatment with onconase, an antitumor ribonuclease. $J$ Natl Cancer Inst, 88:747-53.

Shacter E, Williams JA, Hinson RM, et al. 2000. Oxidative stress interferes with cancer chemotherapy: inhibition of lymphoma cell apoptosis and phagocytosis. Blood, 96:307-13.

Vasandani VM, Wu YN, Mikulski SM, et al. 1996. Molecular determinants in the plasma clearance and tissue distribution of ribonucleases of the ribonuclease A superfamily. Cancer Res, 56:4180-6.

Vasandani VM, Burris JA, Sung C. 1999. Reversible nephrotoxicity of onconase and effect of lysine $\mathrm{pH}$ on renal onconase uptake. Cancer Chemother Pharmacol, 44:164-9.

Vogelzang N, Taub R, Shin D, et al. 2000. Phase III randomized trial of onconase (ONC) versus doxorubicin (DOX) in patients (Pts) with unresectable malignant mesothelioma (UMM): analysis of survival [abstract]. Proc Am Soc Clin Oncol, 2274.

Vogelzang NJ, Aklilu M, Stadler WM, et al. 2001. A Phase II trial of weekly intravenous ranpirnase (Onconase), a novel ribonuclease in patients with metastatic kidney cancer. Invest New Drugs, 3:255-60.

Vogelzang NJ, Porta C, Mutti L. 2005. New agents in the management of advanced mesothelioma. Semin Oncol, 32:336-50.

Wu Y, Mikulski SM, Ardelt W, et al. 1993. A cytotoxic ribonuclease. Study of the mechanism of onconase cytotoxicity. J Biol Chem, 268:10686-93. 
